\title{
Disparities in excess deaths from the COVID-19 pandemic among migrant workers in Kuwait
}

\author{
Barrak Alahmad ${ }^{1,2}$, Dawoud AlMekhled ${ }^{3}$, Ayah Odeh $^{4}$, Dalia Albloushi ${ }^{5}$ and Janvier Gasana ${ }^{1 *}$
}

\begin{abstract}
Background: The actual human cost of the pandemic cannot be viewed through the COVID-19 mortality rates alone, especially when the pandemic is widening the existing health disparities among different subpopulations within the same society. In Kuwait, migrant workers were already disproportionately impacted by COVID-19 and its unintended consequences. The totality of that effect on mortality is yet to be fully understood.

Objective: To estimate excess deaths in the pandemic year of 2020 among the Kuwaiti and non-Kuwaiti migrant populations.

Methods: We analyzed publicly available retrospective data in Kuwait on total annual mortality historically (from 2005 to 2019) and in 2020. We fitted a quasi-poisson generalized linear model adjusted for yearly trend and nationality to estimate the expected deaths in 2020 in the absence of the pandemic. We calculated excess deaths as the difference between observed and expected mortality for the year of the pandemic in both Kuwaitis and non-Kuwaitis.

Results: In the absence of the pandemic, we expected the total mortality in Kuwait to be 6629 (95\% Cl: 6472 to 6789) deaths. However, the observed total mortality in 2020 was 9975 deaths; about 3346 (3186 to 3503) more deaths above the expected historical trend. Deaths among migrant workers would have been approximately $71.9 \%$ (67.8 to 76.0) lower in the absence of the pandemic. On the other hand, deaths among Kuwaitis would have been $32.4 \%$ (29.3 to 35.6) lower if the country had not been hit by the pandemic.

Conclusion: The burden of mortality brought on by the COVID-19 pandemic is substantially higher than what the official tally might suggest. Systematically disadvantaged migrant workers shouldered a larger burden of deaths in the pandemic year. Public health interventions must consider structural and societal determinants that give rise to the health disparities seen among migrant workers.
\end{abstract}

Keywords: Migrant workers, Excess deaths, Health disparities, Kuwait, COVID-19, Pandemic

\footnotetext{
* Correspondence: janvier.gasana@ku.edu.kw

'Department of Environmental and Occupational Health, Faculty of Public Health, Kuwait University, Kuwait City, Kuwait

Full list of author information is available at the end of the article
}

(c) The Author(s). 2021 Open Access This article is licensed under a Creative Commons Attribution 4.0 International License, which permits use, sharing, adaptation, distribution and reproduction in any medium or format, as long as you give appropriate credit to the original author(s) and the source, provide a link to the Creative Commons licence, and indicate if changes were made. The images or other third party material in this article are included in the article's Creative Commons licence, unless indicated otherwise in a credit line to the material. If material is not included in the article's Creative Commons licence and your intended use is not permitted by statutory regulation or exceeds the permitted use, you will need to obtain permission directly from the copyright holder. To view a copy of this licence, visit http://creativecommons.org/licenses/by/4.0/ The Creative Commons Public Domain Dedication waiver (http://creativecommons.org/publicdomain/zero/1.0/) applies to the data made available in this article, unless otherwise stated in a credit line to the data. 


\section{Introduction}

The coronavirus disease 2019 (COVID-19) pandemic triggered a mass disruption to social, economic, and environmental modes of operation. Most alarming is the disruption to the health system caused by the pandemic, that will manifest into the overall population health [1]. Governments worldwide have put efforts to mitigate the burden of the pandemic on the healthcare system by reducing access to healthcare in non-urgent circumstances; through cutting down routine testing of other diseases, cancellations of elective surgeries and in-person consultations with patients with chronic diseases $[1,2]$. The COVID-19 mortality rates alone do not indicate the total burden of disease during the pandemic year as disruptions to healthcare access are likely to result in greater mortality. Furthermore, due to differences in death reporting protocols, relying on COVID-19 mortality rates as a comparator is not a reliable way to measure the effects of the pandemic between countries [3].

In order to assess the overall impact of the pandemic, excess death must be carefully examined [3, 4]. Excess death is the difference between the number of deaths from all causes observed during a public health crisis and the expected number of deaths in its absence or in otherwise 'normal' conditions. This provides an efficient mortality surveillance strategy accounting for the indirect burden of disease caused by disruptions to the access and use of healthcare [4]. This estimate overcomes the variability between different countries in how they report COVID-19 deaths as well as allowing for a clearer indication of the impact of the pandemic in each country. Excess deaths have been previously used to assess the human costs of prior pandemics and to estimate the impact of climate change on mortality [5-9].

Ethnic and racial disparities have existed in healthcare access and utilization prior to the COVID-19 pandemic $[1,10]$. In the US alone, the Black community has experienced lower standards of health, lower life expectancies, and higher mortalities compared to their white counterparts $[11,12]$. Similarly, in Kuwait, migrant worker communities' differential access to education, housing, healthcare and employment reduces their quality of overall health. Migrant workers who make up the majority of the population are employed in low skilled labour jobs and domestic work, facing precarious working conditions, financial hardships and inadequate housing [13]. Having little knowledge of the health insurance systems and language barriers makes it difficult for them to access healthcare when needed. Additionally, migrants are more likely to work in occupations that increase the risk of transmission and are generally excluded from protections in public policies [13]. All these factors contribute to a structural and systematic health disadvantage that gives rise to health disparities in Kuwait amongst ethnic populations.
Kuwait has been severely affected by COVID-19. Due to the imposition of lockdowns and curfews to mitigate transmission rates, the country has witnessed a disruption to healthcare access, delivery, and provision. Kuwait has a population of 4.7 million, with a demographic profile consisting of approximately two-thirds non-Kuwaiti [14]. Previous studies in Kuwait have highlighted the disparities in COVID-19 exposure risk and adverse health outcomes [13, 15-17]. However, to date there has been no study assessing the excess deaths in Kuwait as well as between Kuwaitis and non-Kuwaitis attributable to the COVID-19 pandemic. This study aims to estimate the excess deaths in the pandemic year of 2020 among the Kuwaiti and non-Kuwaiti subpopulations.

\section{Methods}

\section{Data sources}

Data was collated from publicly available official sources by the Kuwaiti Government. Annual population estimates by nationality from 2005 to 2020 was obtained from the Public Authority for Civil Information (accessible: https:// www.paci.gov.kw/stat/TimeSeries.aspx). Similarly, deaths by nationality in 2005 and 2020 were obtained from the same source. In an additional analysis, we used historical mortality data between 2001 and 2018 by nationality from annual mortality reports prepared by the government's Central Statistical Bureau (accessible: https://csb.gov.kw/ Pages/Statistics?ID=10\&ParentCatID=1). The compiled data that supports this analysis is available in the supplemental material (Supplemental Raw Data).

To compare our dataset with other countries, we used the World Mortality Dataset (accessible: https://github. com/akarlinsky/world_mortality) and the COVID-19 excess deaths data from 'Our World In Data' - a project of the Global Change Data Lab, a registered charity in England and Wales that is run by Oxford Marin School, University of Oxford (accessible: https://ourworldindata. org/excess-mortality-covid) [18]. The methods used to calculate excess deaths in other countries are described elsewhere [19]. We summed weekly or monthly observed and expected deaths from countries that provided complete datasets.

\section{Statistical analysis}

We calculated an unadjusted death rate as the number of deaths divided by the population estimate per 1000 individuals per year. We used two methods to calculate expected deaths in 2020. First, we fitted a generalized linear regression for rates of annual deaths from 2001 to 2019 with a quasi-poisson distribution to account for overdispersion. We included two independent variables: linear trend for year, and a dummy variable for nationality (Kuwaiti vs. Non-Kuwaiti). Additionally, we included an offset term log (population) to model the rate rather 
than counts and account for changes in population dynamics over the years. We then used the model to predict the expected 2020 deaths with 95\% confidence intervals (CI) for Kuwaitis and non-Kuwaitis. In a sensitivity analysis, to check for non-linearity of yearly trends of mortality rates, we fitted a generalized additive model with penalized splines for years.

Further, we used the simple rolling average method to calculate the expected deaths in 2020. We averaged deaths in the last 5 years (2015 to 2019) for Kuwaitis and non-Kuwaitis. Then, we calculated the uncertainty around the averaging estimate $(95 \% \mathrm{CI})$ by adding and subtracting the estimate from 1.96 times the square root of the estimate [20].

Excess deaths were calculated as observed deaths minus expected deaths in 2020 for each subpopulation. Percent increase in excess deaths was calculated by subtracting expected from observed deaths and then dividing by expected deaths. A similar approach was carried out for upper and lower bounds of expected deaths from the two methods.

\section{Results}

The number of deaths and death rates per 1000 from 2015 to 2020 are presented in Table 1. Overall, 9975 deaths were reported in 2020, with an overall rate of 2.1 deaths per 1000 population; a marked increase compared to the previous 5 years. Similarly, when examined by nationality, the total number of deaths among Kuwaitis in 2020 was 4756 with a rate of 3.3 deaths per 1000 population, while non-Kuwait deaths totaled to 5219 deaths with a rate of 1.6 per 1000 population.

Over the entire historical period of annual mortality examined, there was a general downward trend. The pandemic year of 2020 clearly exhibited a large increase in mortality rate compared to the previous years. This was seen among non-Kuwaitis, increasing from 1.0 to 1.6, and among Kuwaitis as well, having increased from 2.6 to 3.3 deaths per 1000 population (Fig. 1).

Regression analysis showed that expected deaths were significantly lower than observed deaths in 2020, with a total of 3346 (95\% CI: 3186 to 3503) excess deaths occurring, a 50.5\% (95\% CI: 46.9 to 54.1) increase. An estimated 32.4\% (95\% CI: 29.3 to 35.6) increase in excess deaths was seen among Kuwaitis while $71.9 \%$ (95\%CI: 67.8 to 76.0 ) were seen among non-Kuwaitis. Penalized spline on yearly trends did not suggest evidence of nonlinearity (degrees of freedom $=1$ ). Simple average estimates showed similar results but slightly higher than the regression analysis, with 3580 (95\% CI: 3424 to 3737) more individuals expected dying, accounting for $56.0 \%$ increase (95\%CI: 52.3 to 59.9) as shown in Table 2. Using the Central Statistical Bureau historical mortality, the results provided a similar pattern, yet the estimates were slightly lower (Supplemental Table A).

\section{Discussion}

With the pandemic widening the existing health disparities among different subpopulations within the same society, we observed migrant workers shouldering a larger burden of mortality. There were more than two thousand overall excess deaths amongst non-Kuwaitis translating into more than a $71 \%$ increase in expected mortality. In contrast, the Kuwaiti population also experienced a deadly year, yet the percentage increase was nearly $32 \%$, not as dramatic as non-Kuwaitis. That is, nearly a 40-percentage point difference between the two subpopulations in an absolute scale.

Kuwait, like other Gulf Countries, is host to a huge expatriate population and depends heavily on non-Kuwaiti labor. The majority of which are from South and Southeast Asia, mainly India and the Philippines, who are predominately employed in the service industry and construction work, whereas Egyptians compromise the largest of the non-Kuwaiti Arab population [21, 22]. Strict family visa rules led to these workers coming to Kuwait unaccompanied by families who reside in their home countries and depend on their money transfers to make ends meet. The majority of non-Kuwaitis are young males (between 30 and 49 years), and only $20 \%$ of non-Kuwaitis have an educational attainment beyond high-school [13]. This imbalance in demographic

Table 1 Total mortality counts and death rates in Kuwait from 2015 to 2020

\begin{tabular}{|c|c|c|c|c|c|c|}
\hline \multirow[t]{2}{*}{ Year } & \multicolumn{2}{|l|}{ Total } & \multicolumn{2}{|c|}{ Kuwaitis } & \multicolumn{2}{|c|}{ Non-Kuwaitis } \\
\hline & Deaths & Rate per 1000 & Deaths & Rate per 1000 & Deaths & Rate per 1000 \\
\hline 2015 & 6099 & 1.4 & 3261 & 2.5 & 2838 & 1.0 \\
\hline 2016 & 6248 & 1.4 & 3439 & 2.6 & 2809 & 0.9 \\
\hline 2017 & 6356 & 1.4 & 3432 & 2.5 & 2924 & 0.9 \\
\hline 2018 & 6374 & 1.4 & 3433 & 2.4 & 2941 & 0.9 \\
\hline 2019 & 6896 & 1.4 & 3687 & 2.6 & 3209 & 1.0 \\
\hline 2020 & 9975 & 2.1 & 4756 & 3.3 & 5219 & 1.6 \\
\hline
\end{tabular}

Source: Public Authority for Civil Information, Government of Kuwait 


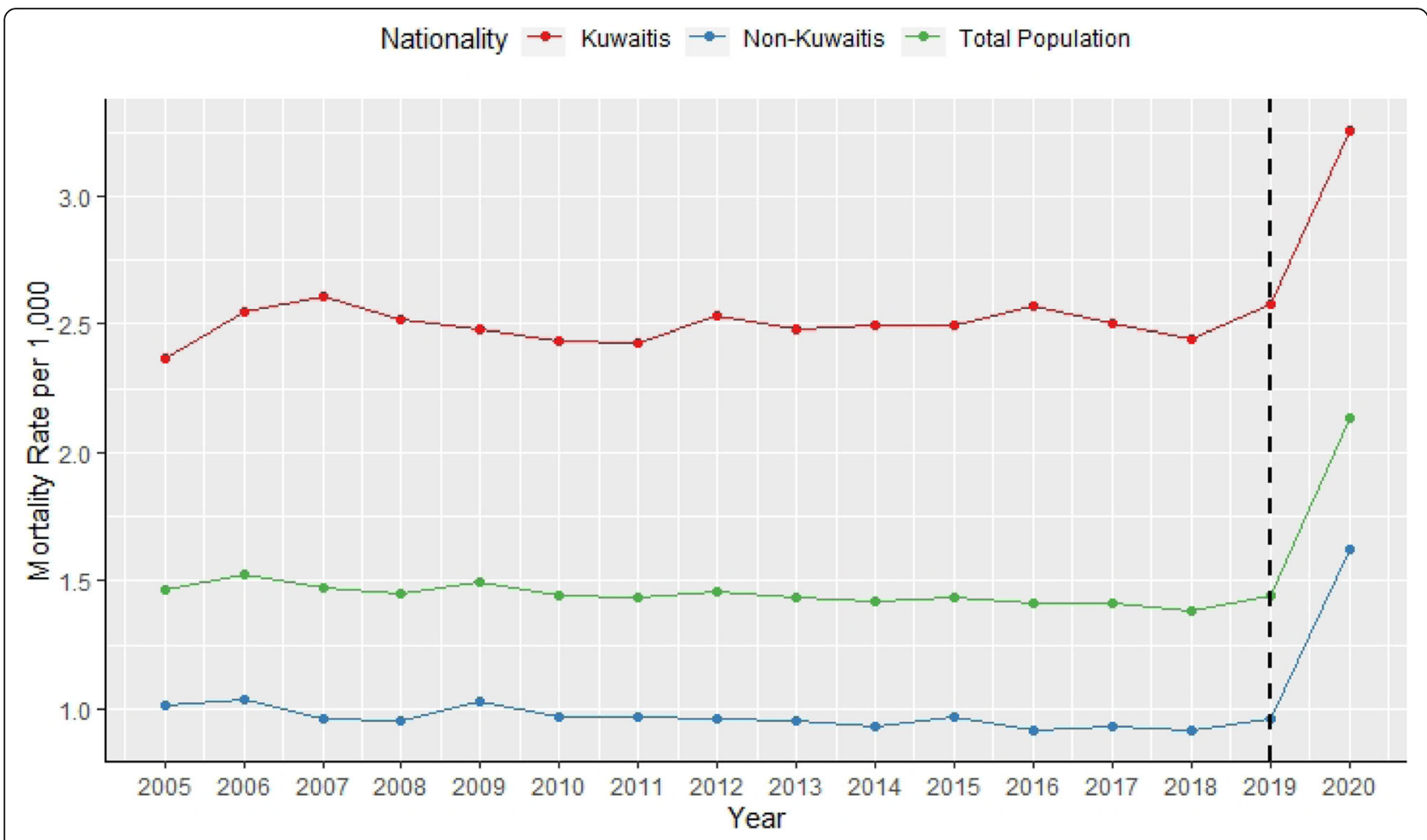

Fig. 1 Historical mortality rates in Kuwait per 1000 population from 2005 to 2020

profiles between the Kuwaiti and non-Kuwaiti population has propelled the state to designate geographical regions as family-only. Hence, isolating the workers from the rest of the population based on gender and nationality in regions that experienced an exponential growth, inevitably straining the infrastructure systems [21]. Moreover, such imbalances in the structure of the Kuwaiti society are bound to have an effect on the distribution of income. The average Kuwaiti income earner earns around KD 1410, while the average non-Kuwaiti income earner earns approximately less than half of that income [23].

Living in cramped and overcrowded homes with poor ventilation while sharing amenities increases the predisposition to COVID-19 infection. In addition, the poor working conditions of migrants could lead to undiagnosed health conditions that when left untreated, may worsen their overall health, leading to severe COVID-19 infections [15]. Even though the basic healthcare needs of migrant workers are covered by national health

Table 2 Estimates of expected and excess deaths in 2020 stratified by nationality

\begin{tabular}{|c|c|c|c|}
\hline & Total & Kuwaitis & Non-Kuwaitis \\
\hline Observed Deaths in $2020^{a}$ & 9975 & 4756 & 5219 \\
\hline \multicolumn{4}{|l|}{ Regression Estimate: } \\
\hline Expected Deaths (95\% Cl) & 6629 (6472 to 6789) & 3592 (3508 to 3678) & 3036 (2964 to 3111) \\
\hline Excess Deaths (95\% Cl) & 3346 (3186 to 3503 ) & 1164 (1078 to 1247$)$ & 2183 (2108 to 2255) \\
\hline Excess Deaths \% (95\% Cl) & 50.5 (46.9 to 54.1) & 32.4 (29.3 to 35.6) & 71.9 (67.8 to 76.0 ) \\
\hline \multicolumn{4}{|l|}{ Simple Averaging Estimate: } \\
\hline Expected Deaths (95\% Cl) & 6395 (6238 to 6551) & 3450 (3335 to 3566) & 2944 (2838 to 3051) \\
\hline Excess Deaths (95\% Cl) & 3580 (3424 to 3737 ) & 1306 (1190 to 1420$)$ & 2275 (2168 to 2381) \\
\hline Excess Deaths \% (95\% CI) & $56.0(52.3$ to 59.9$)$ & 37.8 (33.9 to 42.6$)$ & 77.2 (71.1 to 83.9$)$ \\
\hline
\end{tabular}

a Source: Public Authority for Civil Information, Government of Kuwait 
insurance schemes, access is hindered by limited knowledge of the healthcare system. Moreover, language barriers hamper public health messaging and training on social distancing measures making it difficult for individuals to adhere to COVID-safe practices which increases the risk of infection [13].

The non-Kuwaiti population is comprised of migrant workers who are in working age and hence relatively younger than Kuwaiti adults [14]. The migrant worker subpopulation is generally considered healthier than their counterparts [24]. This can be clearly seen as the historical death rates among the Kuwaiti population was nearly 2.5 -fold higher than non-Kuwaitis. However, due to the pandemic alone, despite them being relatively younger, non-Kuwaitis experienced a much higher percentage of excess deaths. This emphasizes that migrant workers are particularly vulnerable to COVID-19 infections and its social, economic and environmental consequences. Migrant workers in Kuwait had more than a two-fold increase in the odds of requiring intensive care or dying from COVID-19 compared to Kuwaitis after adjustment for baseline characteristics including age and co-morbidities [15, 25]. Significant spreading and clustering outbreaks of COVID-19 in Kuwait were shown to be in areas densely populated by migrant workers [16, 17]. A cumulative risk assessment of the effects of COVID-19 on migrant workers in Kuwait showed that stressors arising from domains other than the individual level are inseparable from the risks of adverse health [13]. Migrant workers face job and house insecurity, and are sometimes unable to support their daily needs. Additionally, migrant workers in Kuwait were also shown to be especially vulnerable to death from environmental exposures such as extreme heat, dust storms and air pollution $[26,27]$. Disparities in the excess deaths during the pandemic is another confirmatory piece of evidence of structural health inequities that are based on nationality and migrant status in the state of Kuwait.

There are multiple aspects to explain the disparities observed amongst the global excess deaths in a public health crisis. First, the social and environmental determinants of health have been inversely associated with noncommunicable diseases (NCDs); those most deprived are more likely to suffer from NCDs than their more privileged counterparts [28, 29]. Thus, among other things, it is possible that ethnic and racial disparities in COVID-19 mortality and excess deaths are attributable to a higher prevalence of NCDs in marginalized communities. Second, delayed presentation - either due to personal fear of contracting the virus or difficultly accessing the healthcare system, is associated with more extensive disease presentation and therefore requires more aggressive interventions. For instance, a rise in surgical emergencies such as obstructed hernia with bowel ischemia, diabetic foot ulcers requiring amputation and appendicular abscess was noted during this pandemic [30]. Another example is the presentation of complications in oncological patients that have arisen due to the temporary halt of elective surgeries [30]. The same has been observed in medical emergencies, specifically with delayed presentation of myocardial infarction being associated with higher mortality and more complications such as fatal left ventricular free wall rupture and tissue necrosis [31, 32]. Furthermore, the global postponement of medical care most likely resulted in a backlog of appointments, procedures, and surgeries due to increase demand and limited resources. This further delay is likely to have an adverse impact on population health [33].

We compared Kuwait's excess deaths percentage of $56.0 \%$ (simple averaging) to a number of other countries from Our World In Data and the World Mortality Dataset tracker of excess deaths $[18,19]$. The method used to predict expected deaths for other countries in the repository included summing deaths over weeks or months. We were not able to do that for Kuwait given our restricted access to only annual deaths. Yet, at face value, excess deaths in Kuwait were still considerably greater than levels observed in other countries like the U.S. and Europe (Supplemental Figure A). For example, the 2020 annual percentage of excess deaths in the U.S., Spain and Italy are estimated to be 19, 18 and 15\%, respectively. Compared to other Gulf states, excess deaths in Kuwait exceeded those from Oman (24\%) and Qatar (14\%). Comparable numbers from other Gulf countries like Saudi Arabia or the United Arab Emirates were not available. Kuwait's numbers are however comparable to South American countries such as Ecuador (63\%), Bolivia (52\%) and Mexico (47\%). Given that the pandemic may lead to fewer deaths from accidental causes, the excess numbers of deaths observed in Kuwait in 2020 are concerningly sizeable. It is acknowledged that COVID-19 mortality figures are underestimates of the actual death toll [34, 35]. By December 31st, 2020, the cumulative COVID-19 official reported mortality in Kuwait was 934 deaths [36]. According to our estimates this leaves an additional 2400 deaths unexplained. COVID-19 deaths alone need to be underestimated by a factor of nearly 3.5 to explain the additional mortality. However, we argue that indirect fatalities from delayed and disrupted care due to cancer, circulatory and other causes may have played a significant role in these deaths.

This study has a number of limitations. At the time of writing, important stratifying data on gender, age, cause of death, co-morbidities and year of migration to Kuwait were not available. Secondly, it was not possible for us to accurately account for population decline among migrant workers in the pandemic year due to unemployment or deportation due to invalid paperwork. However, the non-Kuwaiti population estimate from PACI for 2020 showed a noticeable decline which may reflect such 
changes in population dynamics. This was accounted for in the model as we used log (population) as an offset when estimating the rate of excess deaths. Thirdly, although we present two methods in estimating the expected deaths in 2020, there are more advanced forecasting techniques in predicting expected mortality such as seasonal autoregressive integrated moving average (ARIMA) and machine learning. However, to get accurate estimates using these other methods we would need better temporal resolution (e.g., weekly or monthly mortality data) historically and in 2020 . We were limited in obtaining only annual deaths. Daily, weekly, or monthly observed deaths were not publicly available. Because of that, the readers must be cautioned that our overall estimation of excess deaths percentage may be exaggerated. Finally, the disparity in migrant workers excess deaths is restricted to Kuwait and cannot be generalized to other contexts. Yet, the picture is unlikely to be completely different in other Gulf countries that are hosts to millions of migrant workers.

\section{Conclusion}

Based on historical annual deaths in Kuwait, the burden of mortality of the COVID-19 pandemic is substantially higher than what the official sources might suggest. Systematically disadvantaged marginalized subpopulations like migrant workers are coming off worse and bearing a larger weight from the pandemic. Population health was severely and differentially impacted by COVID-19 warranting public health interventions that are sensitive to underlying structural and societal determinants that generate stark inequities and disparities.

\section{Supplementary Information}

The online version contains supplementary material available at https://doi. org/10.1186/s12889-021-11693-w.

Additional file 1.

\section{Acknowledgements}

We take this opportunity of acknowledge and thank Kuwait Foundation for the Advancement of Sciences (KFAS) that funded our COVID-19 related project that shed a light on the migrant workers' morbidity and mortality due to COVID-19 and prompted the drafting this manuscript. Indeed, as part of the Emergency Resilience Program in Kuwait, led by KFAS, this project was funded by KFAS under the project code: CORONA PROP 134, titled: 'Strengthening Capacity for Protection of Occupational Health and Safety of Health Care Workers and Non-healthcare Workers (Migrant Workers) During COVID19 Pandemic and Beyond'. We would like to thank Lubna Hazem and Danah Alhamlan for collecting COVID-19 data from the Ministry of Health in order to document the existing situation of COVID-19 in Kuwait.

\section{Authors' contributions}

BA wrote the main manuscript text and analyzed the data. DAM,AO, and DAB wrote the main manuscript text. JG supervised the work and reviewed the manuscript. The author(s) read and approved the final manuscript.

\section{Funding}

The authors received no funding for this analysis.

\section{Availability of data and materials}

The datasets generated and/or analyzed during the current study are available in the supplemental material in csv (comma separated values file) format. The World Mortality Dataset is available from this repository; https:// github.com/akarlinsky/world_mortality

\section{Declarations}

Ethics approval and consent to participate

Not applicable: The data that supports this analysis is fully and freely available to download online.

\section{Consent for publication}

Not applicable.

\section{Competing interests}

The authors have no conflict of interests to declare.

\section{Author details}

${ }^{1}$ Department of Environmental and Occupational Health, Faculty of Public Health, Kuwait University, Kuwait City, Kuwait. ${ }^{2}$ Environmental Health Department, Harvard T.H. Chan School of Public Health, Harvard University, Boston, MA, USA. ${ }^{3}$ School of Biomedical Sciences, Faculty of Medicine, Nursing, and Health Sciences, Monash University, Melbourne, Australia. ${ }^{4}$ Department of Health Policy and Management, Faculty of Public Health, Kuwait University, Kuwait City, Kuwait. ${ }^{5}$ Mubarak Al-Kabeer Hospital, Ministry of Health, Hawalli, Kuwait.

Received: 25 March 2021 Accepted: 29 August 2021

Published online: 14 September 2021

\section{References}

1. Blumenthal D, Fowler EJ, Abrams M, Collins SR. Covid-19 - implications for the health care system. N Engl J Med. 2020 Oct 8;383(15):1483-8. https:// doi.org/10.1056/NEJMsb2021088.

2. Moynihan R, Sanders S, Michaleff ZA, Scott AM, Clark J, To EJ, et al. Impact of COVID-19 pandemic on utilisation of healthcare services: a systematic review. BMJ Open. 2021;11(3):e045343. https://doi.org/10.1136/bmjopen-202 0-045343.

3. Beaney T, Clarke JM, Jain V, Golestaneh AK, Lyons G, Salman D, et al. Excess mortality: the gold standard in measuring the impact of COVID-19 worldwide? J R Soc Med. 2020;113(9):329-34. https://doi.org/10.1177/0141 076820956802 .

4. Setel $\mathrm{P}$, AbouZahr $\mathrm{C}$, Atuheire EB, Bratschi M, Cercone E, Chinganya O, et al. Mortality surveillance during the COVID-19 pandemic. Bull World Health Organ. 2020;98(6):374. https://doi.org/10.2471/BLT.20.263194.

5. Lee VJ, Yap J, Ong JBS, Chan K-P, Lin RTP, Chan SP, et al. Influenza excess mortality from 1950-2000 in tropical Singapore. PLoS One. 2009;4(12):e8096. https://doi.org/10.1371/journal.pone.0008096.

6. Hardelid P, Andrews N, Pebody R. Excess mortality monitoring in England and Wales during the influenza a(H1N1) 2009 pandemic. Epidemiol Infect. 2011;139(9):1431-9. https://doi.org/10.1017/S0950268811000410.

7. Sochas L, Channon AA, Nam S. Counting indirect crisis-related deaths in the context of a low-resilience health system: the case of maternal and neonatal health during the Ebola epidemic in Sierra Leone. Health Policy Plan. 2017;32(suppl_3):iii32-9.

8. Guo Y, Gasparrini A, Li S, Sera F, Vicedo-Cabrera AM, de Sousa Zanotti Stagliorio Coelho M, et al. Quantifying excess deaths related to heatwaves under climate change scenarios: A multicountry time series modelling study. PLoS Med. 2018;15(7):e1002629.

9. Kontis V, Bennett JE, Rashid T, Parks RM, Pearson-Stuttard J, Guillot M, et al Magnitude, demographics and dynamics of the effect of the first wave of the COVID-19 pandemic on all-cause mortality in 21 industrialized countries. Nat Med. 2020;26(12):1919-28. https://doi.org/10.1038/s41591-020-1112-0.

10. Fiscella K, Sanders MR. Racial and ethnic disparities in the quality of health care. Annu Rev Public Health. 2016;37(1):375-94. https://doi.org/10.1146/a nnurev-publhealth-032315-021439.

11. Skarupski KA, de Leon CFM, Bienias JL, Scherr PA, Zack MM, Moriarty DG, et al. Black-white differences in health-related quality of life among older adults. Qual Life Res. 2007;16(2):287-96. https://doi.org/10.1007/s11136-0069115-y. 
12. Kaufman JS, Riddell CA, Harper S. Black and white differences in life expectancy in 4 US states, 1969-2013. Public Health Rep. 2019;134(6):634-42. https://doi.org/10.1177/0033354919878158.

13. Alahmad B, Kurdi H, Colonna K, Gasana J, Agnew J, Fox MA. COVID-19 stressors on migrant workers in Kuwait: cumulative risk considerations. BMJ Glob Health. 2020;5(7):e002995.

14. PACl. The public Authority for Civil Information. Kuwait City: Government of Kuwait; 2020.

15. Hamadah H, Alahmad B, Behbehani M, Al-Youha S, Almazeedi S, Al-Haddad $\mathrm{M}$, et al. COVID-19 clinical outcomes and nationality: results from a Nationwide registry in Kuwait. BMC Public Health. 2020;20(1):1384. https:// doi.org/10.1186/s12889-020-09490-y.

16. Alkhamis MA, Al Youha S, Khajah MM, Ben Haider N, Alhardan S, Nabeel A, et al. Spatiotemporal dynamics of the COVID-19 pandemic in the State of Kuwait. Int J Infect Dis. 2020;98:153-60. https://doi.org/10.1016/j.ijid.2020.06.078.

17. Khadadah F, Al-Shammari AA, Alhashemi A, Alhuwail D, Al-Saif B, Alzaid SN, et al. The effects of non-pharmaceutical interventions on SARS-CoV-2 transmission in different socioeconomic populations in Kuwait: a modeling study. BMC Public Health. 2021;21(1):990. https://doi.org/10.1186/s12889-021-10984-6.

18. Giattino C, Ritchie H, Roser M, Ortiz-Ospina E, Hasell J. Excess mortality during the Coronavirus pandemic (COVID-19). Our World In Data. 202 [cited 2021 Mar 20]. Available from: https://ourworldindata.org/excess-morta lity-covid

19. Karlinsky A, Kobak D. The World Mortality Dataset: Tracking excess mortality across countries during the COVID-19 pandemic. medRxiv. 2021

20. Adair T, Lopez AD, Hudson S. Approaches and methodsfor estimating excess deaths due to COVID-19. Melbourne: Bloomberg Philanthropies Data for Health Initiative, Civil Registration and Vital Statistics Improvement, University of Melbourne; 2020.

21. Gulseven O. Forecasting population and demographic composition of Kuwait until 2030. Int J Econ Financ Issues. 2016;6(4):1429-35.

22. International Organization for Migration. IOM - UN Migration: Kuwait. IOM UN Migration. 2021 [cited 2021 Jun 10]. Available from: https://www.iom. int/countries/kuwait

23. Central Statistical Bureau. Income and Expenditure Household Survey. Kuwait City: Government of Kuwait; 2013. Report No.: Tabel (3-4)

24. McMichael AJ. Standardized mortality ratios and the "healthy worker effect": scratching beneath the surface. J Occup Med. 1976;18(3):165-8. https://doi. org/10.1097/00043764-197603000-00009.

25. Ali H, Alshukry A, Marafie SK, AlRukhayes M, Ali Y, Abbas MB, et al. Outcomes of COVID-19: Disparities by ethnicity. Infect Genet Evol. 2021;87: 104639.

26. Achilleos S, Al-Ozairi E, Alahmad B, Garshick E, Neophytou AM, Bouhamra W et al. Acute effects of air pollution on mortality: a 17-year analysis in Kuwait. Environ Int. 2019;126:476-83. https://doi.org/10.1016/j.envint.2019.01.072.

27. Alahmad B, Shakarchi AF, Khraishah H, Alseaidan M, Gasana J, Al-Hemoud A, et al. Extreme temperatures and mortality in Kuwait: who is vulnerable? Sci Total Environ. 2020;732:139289. https://doi.org/10.1016/j.scitotenv.2020.139289.

28. Williams J, Allen L, Wickramasinghe K, Mikkelsen B, Roberts N, Townsend N. A systematic review of associations between non-communicable diseases and socioeconomic status within low- and lower-middle-income countries. J Glob Health. 2018;8(2):020409. https://doi.org/10.7189/jogh.08.020409.

29. Marmot M, Bell R. Social determinants and non-communicable diseases: time for integrated action. BMJ. 2019;364:1251.

30. Mehanathan PB, Edwards AA, Athisayamani RT. Experience of a surgeon at the emergency department during COVID-19 pandemic. Ann Med Surg (Lond). 2020;60:245-8.

31. Cerrato E, Forno D, Ferro S, Chinaglia A. Characteristics, in-hospital management and outcome of late acute ST-elevation myocardial infarction presenters. J Cardiovasc Med (Hagerstown). 2017;18(8):567-71. https://doi. org/10.2459/JCM.0000000000000527.

32. Albiero R, Seresini G. Subacute left ventricular Free Wall rupture after delayed STEMI presentation during the COVID-19 pandemic. JACC Case Rep. 2020;2(10):1603-9. https://doi.org/10.1016/j.jaccas.2020.06.040.

33. Jain A, Dai T, Bibee K, Myers CG. Covid-19 created an elective surgery backlog: how can hospitals get back on track? Harv Bus Rev. August 10, 2020 Accessible: https://hbr.org/2020/08/covid-19-created-an-elective-surgery-ba cklog-how-can-hospitals-get-back-on-track. Accessed 11 Sept 2021.

34. Vandoros S. Excess mortality during the Covid-19 pandemic: early evidence from England and Wales. Soc Sci Med. 2020;258:113101. https://doi.org/10.1 016/j.socscimed.2020.113101.
35. Tatar M, Habibdoust A, Wilson FA. Analysis of excess deaths during the COVID-19 pandemic in the state of Florida. Am J Public Health. 2021;111(4): 704-7. https://doi.org/10.2105/AJPH.2020.306130.

36. Ministry of Health. COVID-19 Updates - State of Kuwait Live [Internet]. [cited 2021 Mar 23]. Available from: https://corona.e.gov.kw/en

\section{Publisher's Note}

Springer Nature remains neutral with regard to jurisdictional claims in published maps and institutional affiliations.
Ready to submit your research? Choose BMC and benefit from:

- fast, convenient online submission

- thorough peer review by experienced researchers in your field

- rapid publication on acceptance

- support for research data, including large and complex data types

- gold Open Access which fosters wider collaboration and increased citations

- maximum visibility for your research: over $100 \mathrm{M}$ website views per year

At BMC, research is always in progress.

Learn more biomedcentral.com/submissions 